\title{
GLOVES BASED HAND GESTURE RECOGNITION USING INDIAN SIGN LANGUAGE
}

\author{
V. K. Bairagi ${ }^{1}$
}

Abstract-A dumb person can't speak like a normal person. To have communication between dumb people and normal people, gesture communication is challenging one. Image processing based techniques are requiring the camera to be in front of gesture, which may not be possible all the time. To diminish communication gap in between dumb people and normal people, hand gloves are designed which can be easily worn and operated by the dumb person. The resistance sensor and ADXL335 accelerometer sensor are fitted in hand gloves, which can easily measure the bend and movement of hand gesture of the user. These sign signals are converted into a digital signal using ADC. The microcontroller is used to recognition hand gesture. After recognition of gesture, these signals are sent to the android phone via Bluetooth module. The received text signal at an Android phone is converted into speech signal using Text to Speech android app. The converted text to speech output is presented with the help of speaker system so that it will be helpful to normal people to understand sign performed by the dumb person. The LCD module is also used to display recognized gesture at microcontroller.

Keywords-Resistance sensor, ADXL335accelerometer sensor, Bluetooth, Android phone, LPC2138, text to speech app.

\section{INTRODUCTION}

The gesture is one of the nonverbal and nonvocal communication forms in which different parts of bodies are used to form particular kinds of meaningful sentence or message[1]. The gesture is nothing but a movement of body specially hand, face, head and lips to convey or express different ideas. The gesture is special tools in gestureinterpretation to express the thoughts, particular in a dumb community [2][3]. Gestures allow individuals to communicate a variety of emotions and thoughts through body language without the use of words when they speak[4][6]. This research is related to a dumb person which is helpful in converting their gestures into voice signals. The developed tool gives freedom to dumb people to communicate with any normal people. One thing about dumb people is that they can read the words or hear the sound like as a normal people bu can't speak [5]. So this is a difficult task for them. This research work helps to convert their hand gesture signal into an audio signal so that normal people can understand easily. A normal people don't know anything about sign language. This research work is basically valuable for Indian people as Indian sign language is used here.

\section{Sign language:}

Sign languages use different kinds of expression for communication in daily life. More particularly, it is one of the modes of communication for dumb people. Thus, it provides a replacement for the speech based way of communication between dumb people [7] [8]. Sign language recognition is very important in various fields such as engineering, medical also its impact gets on the human society [9]. A sign language recognition system can provide contingency for the dumb people to communicate with normal people without the help of an interpreter. Sign languages are well-designed languages with articulation, investigation, syntax and grammar distinctive from spoken languages [10]. Actually, there is a difference between spoken language and sign language in which spoken language makes use of words continuously, whereas a sign language makes use of several body movements simultaneously in the spatial as well as in temporal space [11].

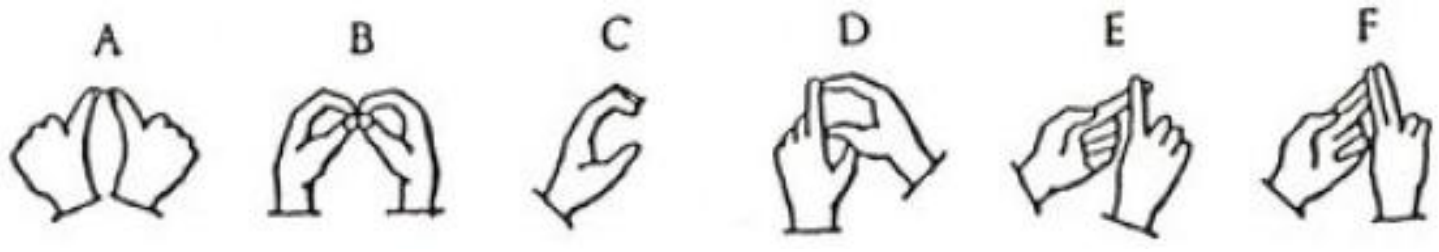

Fig 1 Hand gesture using both hands [3]

This research work is implemented as per the shown fig 1 using two hand gestures for sign language recognition purpose. The gesture can be performed either using one hand or two hands. There is a difference between one hand gesture and two hand gestures. The presented research work is based on two hand gesture for implementation purpose. The Indian sign language is

\footnotetext{
1 Associate Professor, Department of Electronics \& Telecomm. Engineering, AISSMS-Institute of Information Technology, Pune,
} Maharashtra, India 
one of the standard sign language used in many different regions. Its origin is basically from British sign language and American Sign Language. There are different ways to perform sign language such as dynamic or static, but dynamic hand gesture recognition is difficult one. This work is using the static hand gesture for recognizing hand gesture. This method is easy to implement and highly accurate.

\section{BLOCK DIAGRAM}

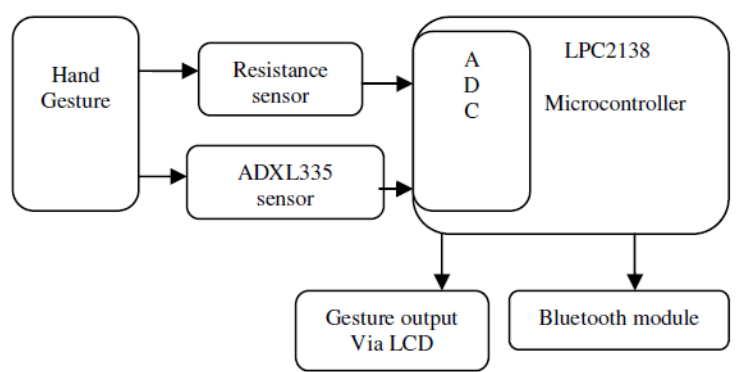

Fig 2 a Gesture Recognition Section via Microcontroller

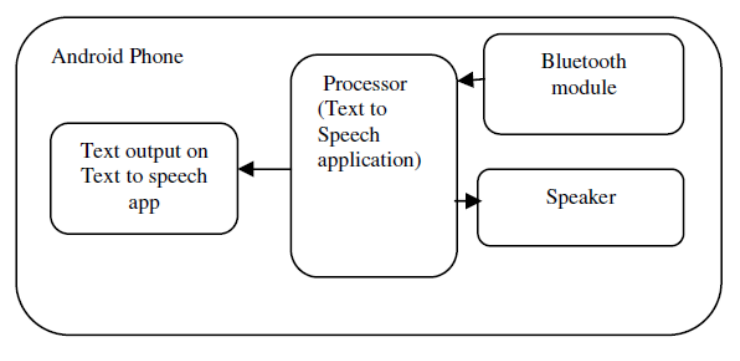

Fig $2 b$ Text to Speech Converter Section via Android Phone

Fig 2 Hand Gesture Recognition System

Figure 2a shows Gesture Recognition Section via Microcontroller. And figure 2b shows Text to Speech Converter Section via Android Phone

\section{Description of components:}

1. Flex / Resistance sensor [15]: Flex (Resistance) sensor is also called as variable sensor/bent sensor. The value of the resistance sensor gets change when the sensor gets bent. The value of the resistance sensor gets increase as more the sensor bent, so output voltage gets affected. This sensor has three connectors namely ground, live, and output which helps to connect to other devices. The bend sensor has resistance range between $10 \mathrm{k}_{-}$to $125 \mathrm{k}_{-}$and the input voltage ranges are between $3 \mathrm{~V}$ to $12 \mathrm{~V}$. The output voltage of sensor is around $65 \%$ of $+\mathrm{V}$ when it is straight and when the sensor is bent position, it is around $80 \%$ of $\mathrm{V}+$.

2. ADXL335 accelerometer sensor[16]: ADXL335 accelerometer sensor is movement detection sensor. The accelerometer sensor helps to measure movement in the three axis direction such as $\mathrm{x}, \mathrm{y}, \mathrm{z}$. The accelerometer sensor measures the acceleration gravity in $+/-3 \mathrm{~g}$.

3. HC-05 Bluetooth module[17]: Bluetooth module is used to make wireless communication between two devices. HC-05 Bluetooth module has RF transmit power up to $+4 \mathrm{dBm}$ and typical sensitivity - $80 \mathrm{dBm}$. It has inbuilt antenna to transmit signal/data to other devices.

4. Android phone[18]: Android is operating system based on the Linux kernel widely used in smartphone and tablets. The android 5.1.1" lollipop" has 32 or 64-bit arm architecture. Different apps can be developed according to requirement.

\section{SYSTEM SETUP}

Figure 3 shows the implemented gesture recognition system. In this system, ten resistance sensor and two ADXL335 accelerometer sensors are used to measure bend signal of finger and position of hand respectively. The resistance sensors are mounted on finger on back side, which accelerometer sensor is placed at back side of palm. The data captured from these sensors are sent to the microcontroller for further processing purpose. Once data is recognized at the microcontroller that is sent to the android phone via Bluetooth module.

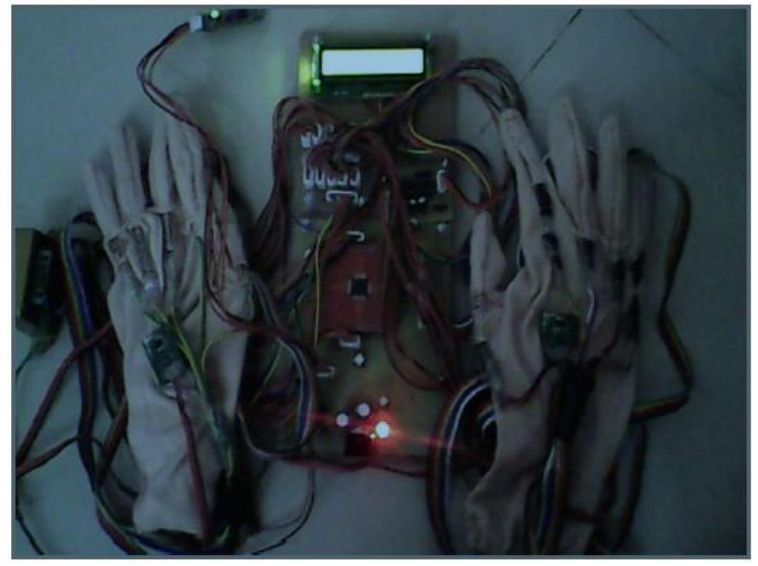


Fig 3 Developed hand gesture recognition system

At android phone side, app is developed which is text to speech converter that helps to convert text signal to voice signal. LCD module is also used to display recognized data near to microcontroller. In this setup max 232IC is used to connect device to computer for further analysis or simulation purpose in this setup different components are used such as LPC2138 microcontroller, resistance sensor, ADXL335 accelerometer sensor, HC-05 Bluetooth module, android phone. Also, 12V power supply is used to supply power to the system.

A. Text to Speech android app:

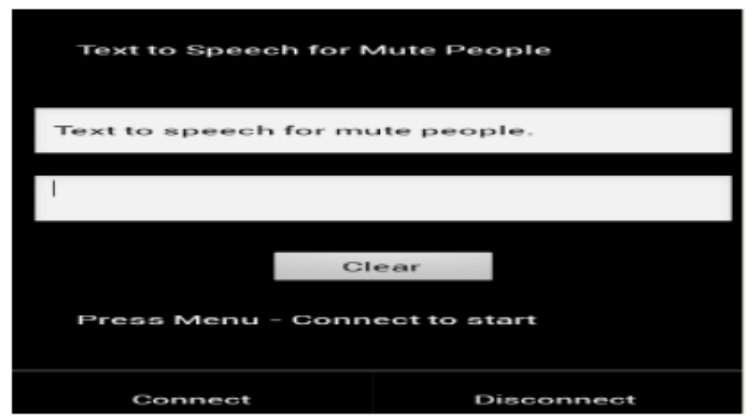

Fig 4 Text to Speech Android App

This text to speech app has been developed in the android to convert text signal to voice signal so as to recognize gesture. The above figure 4 shows the text to speech android app. This application contains different menu such as connect, disconnect, clear that is displayed on the screen of app. The connect menu is used to connect one system to the other system using Bluetooth module so that data transfer can occur in between them. The disconnect menu has used to disconnect system from them if data transfer gets stop. A Clear menu has used to clear all system data which is displayed on the screen of app.

\section{METHODOLOGY}

An analog output is obtained from the accelerometers and resistance sensors. The analog output of the accelerometer sensor and resistance sensor is converted into digital form. An output of the each resistance sensor is given to the separate pin of microcontroller. Microcontroller deals with the resistance sensors one by one. First of all the microcontroller checks the output of the resistance sensor, and calculates its binary value or ASCII value which is converted using ADC, after the calculation of the ASCII values of the first resistance sensor the microcontroller saves its output, and then moves towards the second resistance sensor and calculates its ASCII value in the similar manner, and keeps on calculating the ASCII value of the resistance sensors one by one, having calculated the ASCII value of the outputs of the ten resistance sensors, the microcontroller moves towards the next step of the module, i.e. gesture detection.

At any time, the finger has to be at one of these levels, and the bending of finger is easily determinable. Now the next step is to combine the movement of each finger and name it a particular gesture of the hand. Rather than reading the individual finger, the system now reads the movements of ten fingers as a whole. Initially, the system checks whether the bend is a significant bend or a useless or undefined bend. Next step is to check the data, which was sent by accelerometer detection module i.e. accelerometer sensor at port one of the microcontroller. If the tilt of the hand is also meaningful then it means the gesture as a whole is a meaningful gesture.

If the meaningful gesture is recognized then system sends data to the Bluetooth module. The microcontroller is interfaced with a Bluetooth module which sends wireless data using Bluetooth to an android phone. The phone then receives the data and processes it to understand which symbol is being represented by the hand. In android phone, text to speech app has been developed which converts text value to audio value. In android phone, code for each gesture is defined which is recognized in the microcontroller. Once the received gesture get matched with stored data in the android phone then that data value converted into voice signal.

\section{MODES OF OPERATION}

The hand gloves are designed such that the resistance sensor and accelerometer sensor are fitted on that. The data captured by the sensors are sent continuously to the microcontroller device. In this research work, microcontroller LPC2138 is used for gesture recognition purpose. The whole system is attached directly to the hand gloves. The microcontroller is very useful in hardware and software designing because of flexibility, easy to use. All these features helps implement pre-processing computations on the hand glove.

\section{- Calibration:}


In calibration mode, the user requires first to calibrate the glove. In the first stage, record the $\mathrm{min} / \mathrm{max}$ value that is producing while performing gesture. In this process, user requires to bend or straighten all fingers as well as move the hand in any direction. Once all the sensors values are calibrated then decide the threshold point for each sensor for recognizing hand gesture while user performed the gesture [13].

\section{- Training:}

After calibration, the user requires to train the gesture for recognizing the hand gesture. In this mode, according to the hand gesture assign the meaningful sentence or data and store in the microcontroller memory. This mode of operation is very simple in gesture adding and deleting purpose. In this phase, for each sentence requires assigning mean value of used sensor, if these matches then particular gesture get performed [14].

\section{RESULTS}

In gesture recognition system, sign language of two hands which is recognized using resistance sensor and ADXL335 accelerometer sensor. These two sensors help to recognize bend in finger and position of hand i.e. vertical or horizontal respectively. So using these two sensors, different database is created which is shown below in the table1 and 2.

- Database of system:

Table1: Gesture database for Alphabets Sign

\begin{tabular}{|c|c|c|c|c|c|c|c|c|c|c|c|c|}
\hline \multirow[t]{2}{*}{$\begin{array}{l}\text { Alph } \\
\text { abets }\end{array}$} & \multicolumn{5}{|c|}{$\begin{array}{l}\text { Right-Hand } \\
\text { resistance } \\
\text { sensor }\end{array}$} & \multicolumn{5}{|c|}{$\begin{array}{c}\text { Left-Hand } \\
\text { resistance sensor }\end{array}$} & \multicolumn{2}{|c|}{ Accelerometer sensor } \\
\hline & 1 & 2 & 3 & 4 & 5 & \begin{tabular}{l|l}
6 & \\
\end{tabular} & 7 & 8 & 9 & 10 & Right & Left \\
\hline $\mathrm{A}$ & \begin{tabular}{|l|}
1 \\
\end{tabular} & 0 & 0 & 0 & 0 & 1 & 0 & 0 & 0 & 0 & Undefined & Undefined \\
\hline B & 0 & 0 & 1 & 1 & 1 & 0 & 0 & 1 & 1 & 1 & Undefined & Undefined \\
\hline $\mathrm{C}$ & 1 & 1 & 0 & 0 & 0 & 1 & 1 & 1 & 1 & 1 & $\mathrm{~V}$ & Undefined \\
\hline $\mathrm{D}$ & 0 & 1 & 0 & 0 & 0 & 1 & 1 & 0 & 0 & 0 & Undefined & Undefined \\
\hline $\mathrm{E}$ & 0 & 1 & 0 & 0 & 0 & 1 & 0 & 0 & 0 & 0 & Undefined & $\mathrm{H}$ \\
\hline $\mathrm{F}$ & 0 & 1 & 1 & 0 & 0 & 0 & 1 & 1 & 0 & 0 & Undefined & $\mathrm{H}$ \\
\hline G & 0 & 0 & 0 & 0 & 0 & 0 & 0 & 0 & 0 & 0 & Undefined & Undefined \\
\hline $\mathrm{H}$ & 1 & 1 & 1 & 1 & 1 & 1 & 1 & 1 & 1 & 1 & $\mathrm{H}$ & V \\
\hline I & 0 & 1 & 0 & 0 & 0 & 1 & 1 & 1 & 1 & 1 & Undefined & Undefined \\
\hline $\mathbf{J}$ & 0 & 0 & 0 & 0 & 0 & 0 & 1 & 0 & 0 & 0 & Undefined & Undefined \\
\hline $\mathrm{K}$ & 0 & 1 & 0 & 0 & 0 & 0 & 1 & 0 & 0 & 0 & Undefined & $\mathrm{V}$ \\
\hline $\mathrm{L}$ & 1 & 1 & 0 & 0 & 0 & 0 & 0 & 0 & 0 & 0 & Undefined & Undefined \\
\hline $\mathrm{M}$ & 0 & 1 & 1 & 1 & 0 & 1 & 1 & 1 & 1 & 1 & Undefined & $\mathrm{H}$ \\
\hline $\mathrm{N}$ & 0 & 1 & 1 & 0 & 0 & 1 & 1 & 1 & 1 & 1 & Undefined & $\mathrm{H}$ \\
\hline $\mathrm{O}$ & 0 & 0 & 0 & 0 & 0 & 1 & 1 & 1 & 1 & 1 & Undefined & V \\
\hline$P$ & 0 & 1 & 0 & 0 & 0 & 0 & 0 & 1 & 1 & 1 & V & V \\
\hline$Q$ & 0 & 0 & 0 & 0 & 0 & 0 & 0 & 1 & 1 & 1 & V & V \\
\hline $\mathrm{R}$ & 0 & 0 & 0 & $\begin{array}{ll}0 \\
\end{array}$ & 0 & 1 & 1 & 1 & 1 & 1 & Undefined & $\mathrm{H}$ \\
\hline $\mathrm{S}$ & 0 & 0 & 0 & 0 & 1 & 0 & 0 & 0 & 0 & 1 & Undefined & V \\
\hline $\mathrm{T}$ & 0 & 1 & 0 & 0 & 0 & 0 & 1 & 0 & 0 & 0 & $\mathrm{H}$ & V \\
\hline $\mathrm{U}$ & 0 & 0 & 0 & \begin{tabular}{|l|}
0 \\
\end{tabular} & 0 & 1 & 1 & 0 & 0 & 0 & Undefined & Undefined \\
\hline $\mathrm{V}$ & 0 & 0 & 0 & \begin{tabular}{|l|}
0 \\
\end{tabular} & 0 & 0 & 1 & 1 & 0 & 0 & $\mathrm{~V}$ & Undefined \\
\hline $\mathrm{W}$ & 1 & 1 & 1 & 1 & 1 & 1 & 1 & 1 & 1 & 1 & $\mathrm{H}$ & $\mathrm{H}$ \\
\hline $\mathrm{X}$ & 0 & 0 & 1 & \begin{tabular}{|l|}
0 \\
\end{tabular} & 0 & 0 & 0 & 1 & 0 & 0 & $\mathrm{H}$ & $\mathrm{H}$ \\
\hline $\mathrm{Y}$ & $\begin{array}{ll}0 \\
\end{array}$ & \begin{tabular}{|c|}
1 \\
\end{tabular} & \begin{tabular}{|l|l}
1 & \\
\end{tabular} & \begin{tabular}{|l|}
0 \\
\end{tabular} & 0 & 0 & \begin{tabular}{l|l}
1 & \\
\end{tabular} & 0 & 0 & 0 & $\mathrm{~V}$ & $\mathrm{H}$ \\
\hline
\end{tabular}

The above table 1 shows the alphabets gesture which is defined using binary values as well as accelerometer position. For flex sensor value, binary values are defined. For accelerometer sensor value vertical and horizontal values are assigned according to the position of hand. For each alphabets gesture, binary coding, as well as accelerometer values are assigned because for same gesture we can use accelerometer position according to it so that there should not exist conflict in between these gestures.

Table 2 shows the hand gesture sign for various sentences. To recognize these gesture signals, resistance sensor, as well as accelerometer, are used as sensors. For each gesture signal binary value is assigned as for resistance sensor bend reading and for accelerometer sensor values assigned as vertical and horizontal position. So likewise the database is created. 
Table 2: Gesture database for Numbers

\begin{tabular}{|c|c|c|c|c|c|c|c|c|c|c|}
\hline \multirow{3}{*}{ Numbers } & \multicolumn{4}{|c|}{$\begin{array}{c}\text { Right hand } \\
\text { resistance sensor }\end{array}$} & \multicolumn{5}{|c|}{ Left-hand } \\
\cline { 2 - 12 } & $\mathbf{1}$ & $\mathbf{2}$ & $\mathbf{3}$ & $\mathbf{4}$ & $\mathbf{5}$ & $\mathbf{6}$ & $\mathbf{7}$ & $\mathbf{8}$ & $\mathbf{9}$ & $\mathbf{1 0}$ \\
\hline 1 & 0 & 1 & 0 & 0 & 0 & 0 & 0 & 0 & 0 & 0 \\
\hline 2 & 0 & 1 & 1 & 0 & 0 & 0 & 0 & 0 & 0 & 0 \\
\hline 3 & 0 & 1 & 1 & 1 & 0 & 0 & 0 & 0 & 0 & 0 \\
\hline 4 & 0 & 1 & 1 & 1 & 1 & 0 & 0 & 0 & 0 & 0 \\
\hline 5 & 1 & 1 & 1 & 1 & 1 & 0 & 0 & 0 & 0 & 0 \\
\hline 6 & 1 & 1 & 1 & 1 & 1 & 0 & 1 & 0 & 0 & 0 \\
\hline 7 & 1 & 1 & 1 & 1 & 1 & 0 & 1 & 1 & 0 & 0 \\
\hline 8 & 1 & 1 & 1 & 1 & 1 & 0 & 1 & 1 & 1 & 0 \\
\hline 9 & 1 & 1 & 1 & 1 & 1 & 0 & 1 & 1 & 1 & 1 \\
\hline 10 & 1 & 1 & 1 & 1 & 1 & 1 & 1 & 1 & 1 & 1 \\
\hline
\end{tabular}

\section{- Threshold values for resistance sensor:}

The below table 3 shows, that tested resistance sensor values at different angle likewise 0, 30, 60 etc. The above reading is tested for two resistance sensor such as 2.2" and 4.2" length using DMM instrument.

Table 3: Threshold values for resistance sensor

\begin{tabular}{|c|c|c|c|c|c|c|c|}
\hline \multirow{2}{*}{ Sensor } & \multicolumn{7}{|c|}{ Degree of bend } \\
\cline { 2 - 8 } & $\mathbf{0}^{\circ}$ & $\mathbf{3 0}^{\circ}$ & $\mathbf{6 0}^{\circ}$ & $\mathbf{9 0}^{\circ}$ & $\mathbf{1 2 0}^{\circ}$ & $\mathbf{1 5 0}^{\circ}$ & $\mathbf{1 8 0}^{\circ}$ \\
\hline $\begin{array}{c}\text { Resistance } \\
2.2^{\prime \prime}(\mathrm{V})\end{array}$ & 1.79 & 1.93 & 2.50 & 3.04 & 3.12 & 3.22 & 3.29 \\
\hline $\begin{array}{c}\text { Resistance } \\
4.2 "(\mathrm{~V})\end{array}$ & 1.40 & 1.65 & 2.02 & 2.15 & 2.21 & 2.32 & 2.40 \\
\hline
\end{tabular}

The following figure 5 has been drawn using these threshold values of resistance sensor for 2.2 " and 4.2" long.

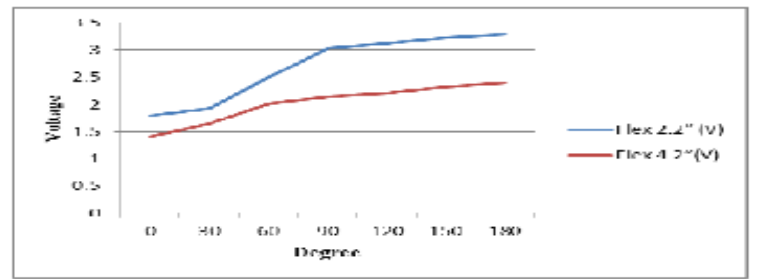

Fig5. Graph for resistance sensor values for various bends of finger

\section{- Simulated Result:}

The hand gesture recognition system is implemented using Indian sign language with the help of resistance sensor and accelerometer sensor. All these captured data is recognized using LPC2138 microcontroller. The captured data or signal is converted into digital signal and that digital value is again converted into ASCII values. For each resistance sensor, particular threshold is assigned value likewise 10 resistance sensor has 10 threshold points. So according to performed gesture, for each gesture, ASCII values are assigned. The following table 4 shows the simulated values for A-Z alphabets. 
Table 4: Simulated values for alphabets A-Z using resistance sensor signal

\begin{tabular}{|c|c|c|c|c|c|c|c|c|c|c|}
\hline $\begin{array}{l}\text { Alph } \\
\text { abets }\end{array}$ & \multicolumn{9}{|c|}{ Right-hand resistance sensor } & \multicolumn{5}{|c|}{ Left-hand resistance sensor } \\
\hline A & 825 & $\mathbf{8 3 0}$ & $\mathbf{8 6 3}$ & $\mathbf{8 4 4}$ & $\mathbf{7 6 6}$ & 841 & $\mathbf{6 9 3}$ & $\mathbf{7 8 5}$ & $\mathbf{7 9 1}$ & $\mathbf{8 2 1}$ \\
\hline B & $\mathbf{7 8 5}$ & $\mathbf{8 2 2}$ & 882 & 865 & 801 & $\mathbf{8 1 5}$ & $\mathbf{6 9 6}$ & 812 & 810 & 844 \\
\hline C & 810 & 850 & $\mathbf{8 6 5}$ & $\mathbf{8 5 4}$ & $\mathbf{7 7 3}$ & 839 & 729 & 815 & 814 & 846 \\
\hline D & $\mathbf{7 8 6}$ & 852 & $\mathbf{8 6 5}$ & $\mathbf{8 4 6}$ & 772 & 841 & 724 & $\mathbf{7 8 8}$ & $\mathbf{7 8 2}$ & $\mathbf{8 2 2}$ \\
\hline E & 812 & 856 & $\mathbf{8 6 4}$ & $\mathbf{8 4 6}$ & $\mathbf{7 6 8}$ & $\mathbf{8 1 9}$ & 722 & $\mathbf{7 9 6}$ & $\mathbf{7 8 8}$ & $\mathbf{8 2 5}$ \\
\hline F & 788 & 853 & 886 & 848 & 766 & 817 & 728 & 816 & 787 & 830 \\
\hline G & $\mathbf{7 8 2}$ & $\mathbf{8 2 0}$ & $\mathbf{8 6 3}$ & $\mathbf{8 4 0}$ & $\mathbf{7 6 2}$ & $\mathbf{8 1 6}$ & $\mathbf{6 9 2}$ & $\mathbf{7 8 4}$ & $\mathbf{7 8 8}$ & $\mathbf{8 1 9}$ \\
\hline H & 828 & 854 & 885 & 868 & 804 & 845 & 728 & 818 & 813 & 848 \\
\hline I & $\mathbf{7 8 3}$ & 856 & $\mathbf{8 6 0}$ & $\mathbf{8 5 0}$ & $\mathbf{7 6 1}$ & 846 & 730 & 815 & 806 & 842 \\
\hline J & $\mathbf{7 8 5}$ & $\mathbf{8 2 5}$ & $\mathbf{8 5 9}$ & $\mathbf{8 4 2}$ & $\mathbf{7 6 3}$ & $\mathbf{8 1 4}$ & 715 & $\mathbf{7 8 8}$ & $\mathbf{7 8 9}$ & $\mathbf{8 1 7}$ \\
\hline K & $\mathbf{7 8 1}$ & 850 & $\mathbf{8 5 5}$ & $\mathbf{8 4 4}$ & $\mathbf{7 5 9}$ & $\mathbf{8 1 0}$ & 731 & $\mathbf{7 8 6}$ & $\mathbf{7 8 0}$ & $\mathbf{8 1 0}$ \\
\hline L & 830 & 859 & $\mathbf{8 5 0}$ & $\mathbf{8 4 0}$ & $\mathbf{7 5 5}$ & $\mathbf{8 0 9}$ & $\mathbf{6 8 8}$ & $\mathbf{7 8 2}$ & $\mathbf{7 7 8}$ & $\mathbf{8 0 8}$ \\
\hline M & $\mathbf{7 8 2}$ & 851 & 887 & 870 & $\mathbf{7 6 0}$ & 844 & 729 & 820 & 815 & 850 \\
\hline N & $\mathbf{7 8 0}$ & 856 & 890 & $\mathbf{8 3 9}$ & $\mathbf{7 5 8}$ & 843 & 732 & 822 & 816 & 851 \\
\hline O & $\mathbf{7 7 8}$ & $\mathbf{8 2 0}$ & $\mathbf{8 6 0}$ & $\mathbf{8 4 6}$ & $\mathbf{7 5 6}$ & 838 & 720 & 815 & 810 & 846 \\
\hline P & $\mathbf{7 7 6}$ & 858 & $\mathbf{8 7 0}$ & $\mathbf{8 4 8}$ & $\mathbf{7 6 0}$ & $\mathbf{8 0 8}$ & $\mathbf{6 8 5}$ & 819 & 818 & 856 \\
\hline Q & $\mathbf{7 8 2}$ & $\mathbf{8 1 9}$ & $\mathbf{8 6 6}$ & $\mathbf{8 4 5}$ & $\mathbf{7 6 2}$ & $\mathbf{8 1 2}$ & $\mathbf{6 9 0}$ & 818 & 814 & 849 \\
\hline R & $\mathbf{7 7 8}$ & $\mathbf{8 1 5}$ & $\mathbf{8 6 4}$ & $\mathbf{8 4 0}$ & $\mathbf{7 5 8}$ & 850 & 732 & 825 & 820 & 858 \\
\hline S & $\mathbf{7 7 4}$ & $\mathbf{8 1 0}$ & $\mathbf{8 6 0}$ & $\mathbf{8 4 2}$ & $\mathbf{8 1 0}$ & $\mathbf{8 1 0}$ & $\mathbf{6 8 0}$ & $\mathbf{7 8 0}$ & $\mathbf{7 7 9}$ & 851 \\
\hline T & $\mathbf{7 7 6}$ & 860 & $\mathbf{8 6 1}$ & $\mathbf{8 4 3}$ & $\mathbf{7 5 4}$ & 844 & $\mathbf{6 8 2}$ & $\mathbf{7 8 1}$ & $\mathbf{7 7 5}$ & $\mathbf{8 1 5}$ \\
\hline U & $\mathbf{7 8 2}$ & $\mathbf{8 1 4}$ & $\mathbf{8 6 7}$ & $\mathbf{8 5 1}$ & $\mathbf{7 5 8}$ & 848 & 725 & 778 & 782 & 819 \\
\hline V & $\mathbf{7 8 0}$ & $\mathbf{8 1 2}$ & $\mathbf{8 6 2}$ & $\mathbf{8 4 8}$ & $\mathbf{7 6 6}$ & $\mathbf{8 2 0}$ & 735 & 830 & 776 & $\mathbf{8 1 4}$ \\
\hline W & $\mathbf{8 2 5}$ & 854 & 880 & 866 & 812 & 856 & 730 & 836 & 816 & 855 \\
\hline X & $\mathbf{7 7 5}$ & $\mathbf{8 2 0}$ & 885 & $\mathbf{8 4 4}$ & $\mathbf{7 6 0}$ & $\mathbf{8 1 5}$ & $\mathbf{6 8 8}$ & 832 & $\mathbf{7 8 0}$ & $\mathbf{8 1 0}$ \\
\hline Y & $\mathbf{7 7 8}$ & 856 & 882 & $\mathbf{8 4 0}$ & $\mathbf{7 6 4}$ & $\mathbf{8 1 8}$ & 728 & $\mathbf{7 8 2}$ & $\mathbf{7 8 5}$ & $\mathbf{8 1 8}$ \\
\hline Z & $\mathbf{7 9 2}$ & $\mathbf{8 3 9}$ & $\mathbf{8 6 5}$ & $\mathbf{8 5 0}$ & $\mathbf{7 7 5}$ & $\mathbf{8 2 2}$ & 721 & 835 & 820 & 860 \\
\hline
\end{tabular}

Table 5 shows the simulated results for numbers 1-10 using resistance sensors values.

Table 5: Simulated values for Numbers using resistance sensor signal

\begin{tabular}{|c|c|c|c|c|c|c|c|c|c|c|}
\hline \multirow{2}{*}{ Numbers } & \multicolumn{9}{|c|}{ Right-hand resistance sensor } & \multicolumn{5}{c|}{ Left-hand resistance } \\
\cline { 2 - 12 } & $\mathbf{1}$ & $\mathbf{2}$ & $\mathbf{3}$ & $\mathbf{4}$ & $\mathbf{5}$ & $\mathbf{6}$ & $\mathbf{7}$ & $\mathbf{8}$ & $\mathbf{9}$ & $\mathbf{1 0}$ \\
\hline 1 & $\mathbf{7 8 0}$ & 860 & $\mathbf{8 6 2}$ & $\mathbf{8 4 4}$ & $\mathbf{7 7 5}$ & $\mathbf{8 1 0}$ & $\mathbf{6 9 5}$ & $\mathbf{7 8 5}$ & $\mathbf{7 8 0}$ & $\mathbf{8 2 5}$ \\
\hline 2 & $\mathbf{7 8 5}$ & 865 & 896 & $\mathbf{8 4 0}$ & $\mathbf{7 6 6}$ & $\mathbf{8 1 5}$ & $\mathbf{6 9 0}$ & $\mathbf{7 8 0}$ & $\mathbf{7 8 5}$ & $\mathbf{8 3 0}$ \\
\hline 3 & $\mathbf{7 8 2}$ & 869 & 899 & 885 & $\mathbf{7 6 1}$ & $\mathbf{8 1 8}$ & $\mathbf{6 8 8}$ & $\mathbf{7 8 3}$ & $\mathbf{7 7 5}$ & $\mathbf{8 2 8}$ \\
\hline 4 & $\mathbf{7 9 0}$ & 872 & 892 & 890 & 810 & $\mathbf{8 2 0}$ & $\mathbf{6 9 5}$ & $\mathbf{7 8 8}$ & $\mathbf{7 8 0}$ & $\mathbf{8 2 5}$ \\
\hline 5 & 835 & 875 & 896 & 892 & 815 & $\mathbf{8 1 5}$ & $\mathbf{6 9 8}$ & $\mathbf{7 7 8}$ & $\mathbf{7 8 6}$ & $\mathbf{8 2 1}$ \\
\hline 6 & 831 & 872 & 893 & 895 & 818 & $\mathbf{8 1 0}$ & $\mathbf{7 3 5}$ & $\mathbf{7 8 2}$ & $\mathbf{7 9 0}$ & $\mathbf{8 2 7}$ \\
\hline 7 & 835 & 869 & 886 & 890 & 812 & $\mathbf{8 2 0}$ & 729 & 825 & $\mathbf{7 9 2}$ & $\mathbf{8 2 8}$ \\
\hline 8 & 830 & 873 & 890 & 885 & 820 & $\mathbf{8 2 2}$ & 725 & 827 & 825 & $\mathbf{8 2 7}$ \\
\hline 9 & 836 & 876 & 888 & 892 & 817 & $\mathbf{8 2 5}$ & 736 & 840 & 832 & 865 \\
\hline 10 & 832 & 880 & 886 & 881 & 822 & 865 & 740 & 844 & 840 & 875 \\
\hline
\end{tabular}

\section{CONCLUSION AND FUTURE SCOPE}

The hand gesture recognition system is very useful for the dumb people to make free and comfortable communication as like normal people. This system is developed using resistance sensor and accelerometer sensor which is more flexible and accurate for measuring hand gesture. The microcontroller is the ultra-low power consumption device which helps to recognize gesture performed by the user. The system designed here support dumb people. Normal peoples are not aware of the Indian sign language. So in this research work, Indian sign language has been implemented for the gesture recognition purpose. It is having advantage over image processing based gesture recognition system as; the presented system does not require any camera to be kept in-front of dumb person to identify his gestures. The accuracy of the system is achieved nearly $98-99 \%$, but it is most of depends on the user's performance.

\section{ACKNOWLEDGMENT}


The Author would like to thanks to Mr. Prakash Gaikwad and Prof. P.B. Mane for providing his valuable support. The author would also thank all the reviewer and editors of this paper.

\section{REFERENCES}

[1] Laura Dipietro, Angelo M. Sabatin, "A Survey of Glove-Based Systems and Their Applications", IEEE Transactions on systems, man, and cybernetics-part c: applications and reviews, Vol-38, No-4, pp-461-482, July 2008.

[2] Rajam, P. Subha and Dr. G Balakrishnan, "Real Time Indian Sign Language Recognition System to aid Deaf and Dumb people", $13^{\text {th }}$ International Conference on Communication Technology (ICCT), pp. 737- 742, 2011.

[3] Sushmita Mitra Tinku Acharya, "Gesture Recognition: A Survey" IEEE TRANSACTIONS ON SYSTEMS, MAN, AND YBERNETICS- PART C: APPLICATIONS AND REVIEWS, VOL. 37, NO. 3, PP- 311- 324, MAY 2007.

[4] H.V Anupreethi and Vijaykumar, "MSP430 based sign language recognizer for dumb patients", Elsevier International conference on modeling optimization and computing, Vol- 38, pp 1374-138, 2012.

[5] Xu Zhang, Xiang Chen, "A Framework for Hand Gesture Recognition Based on Accelerometer and EMG Sensors", IEEE ransactions on system, man, and cybernetics- part A: Systems and Humans, Vol-41, No- 6, pp-1064-1078, Nov 2011.

[6] RuizeXu, Shengli Zhou, and Wen J. Li, “MEMS Accelerometer Based Non-specific User Hand Gesture Recognition”, IEEE Sensor Journal, Vol. 12, No. 5, pp: 1166-1173, May 2012.

[7] Anuja V. Nair et al, “A Review on Indian Sign Language Recognition” International Journal of Computer Applications, Vol 73- No.22 pp 1-5,, July 2013.

[8] G. Fang, W. Gao, and D. Zhao, "Large vocabulary sign language recognition based on fuzzy decision trees," IEEE Trans. Syst., Man, Cybern. A, Syst., Humans, vol. 34, no. 3, pp. 305-314, 2004.

[9] Vikram Sharma M, Vinay Kumar N, Shruti C. Masaguppi, Suma MN, D R. Ambika, "Virtual Talk for Deaf, Mute, Blind and Normal Humans" , Proceeding TIIEC '13 Proceedings of Texas Instruments India Educators' Conference, pp 316-320, 2003.

[10] Gupta, Dhiraj, "Design and development of a low cost Electronic Hand Glove for deaf and blind", 2nd International Conference on Computing for Sustainable Global Development (INDIACom), pp 501-505, 11-13 March 2015.

[11] Preetham C, Ramakrishnan G, Kumar S, Tamse A, Krishnapura N, "Hand Talk-Implementation of a Gesture Recognizing Glove", India Educators' Conference (TIIEC), Texas Instruments, pp: 328 - 331, 2013.

[12] Rajkanna, U. ; Mathankumar, M. ; Gunasekaran, K., "Hand gesture based mobile robot control using PIC microcontroller" International Conference on Circuit, Power and Computing Technologies (ICCPCT), pp: 1687 - 1691, 2014.

[13] Sidek, O ; Hadi, M.A., "Wireless gesture recognition system using MEMS accelerometer", International Symposium on Technology Management and Emerging Technologies (ISTMET), pp $444-447,2014$

[14] Fan Wei, Chen Xiang, Wang Wen-hui, Zhang Xu, Yang Ji-hai, Lantz. V, Wang Kong-qiao, "A Method of Hand Gesture Recognition Based on Multiple Sensors", 4th International Conference on , pp 1-4, 2010.

[15] Datasheet, Spectra symbol, "Flex Sensor", Special edition length product.

[16] Datasheet,"ADXL335 Accelerometer sensor”, sparkfun co.ltd

[17] Datasheet, "Bluetooth module HC-05" Guangzhou HC Information Technology Co.Ltd.

[18] http://www.gsmarena.com/samsung_galaxy_star_pro_s7260-5749.php

[19] NXP semiconductors "Single-chip 16/32-bit microcontrollers" Lpc214x product datasheet, 29 July 2011.

[20] Prakash B Gaikwad, Dr. V.K.Bairagi, "Hand Gesture Recognition for Dumb People using Indian Sign Language", International Journal of Advanced Research in computer Science and Software Engineering, Vol 4, No 12, pp:193-196, 2014

[21] A. M. Sapkal and V. K. Bairagi, "Telemedicine in India: A review challenges and role of image compression," Journal of Medical Imaging and Health Informatics., Vol. 1, no. 4, pp. 300-6, Dec. 2011.

[22] Brijesh Patel, Ravindra Mankar, Vinay Sigedar, V K Bairagi, "ARM-7 Development Board”,International Journal of Advanced Research in Computer Science and Software Engineering, Volume 3, Issue 11, November 2013, pp 1438-1442. 